\title{
Fetal Central Nervous System Development and Alcohol - The Evidence So Far
}

\author{
Musharrat Jabeen Ahmed-Landeryou \\ London South Bank university, Occupational Therapy, Allied Health Sciences, Southwark, \\ London, UK
}

\begin{abstract}
Currently in the UK, there is no absolute guidance about alcohol consumption in pregnancy. The guidance for drinking during pregnancy is one or two units of alcohol one or two times weekly, but conservative advice is to abstain as a cautionary measure [1]. Despite the lack of consensus about the safe levels of alcohol consumption in pregnancy, there is increasing evidence of the impact of alcohol on the developing central nervous system. This article explores the evidence regarding alcohol consumption and its effects on the developing fetal central nervous system.
\end{abstract}

Keywords alcohol, fetal central nervous system (CNS), fetal brain, neuroprotective substances

\section{INTRODUCTION}

This article explores the evidence regarding alcohol consumption and its effects on the developing fetal brain. The following areas will be considered: the current guidance (UK) and trends in alcohol consumption, potential effects of alcohol on the developing fetal central nervous system (CNS), including fetal alcohol syndrome, followed by current research on neuroprotection against alcohol insult for the developing fetal brain.

\section{Current Guidance and Trends in Alcohol Consumption}

Currently, there are no absolute guidelines regarding alcohol consumption in pregnancy. The Royal College of Obstetricians and Gynaecologists (RCOG) [1] have identified increasing evidence demonstrating that excessive alcohol intake during pregnancy is harmful, but make no recommendations for lower levels of alcohol consumption. The guidance for drinking during pregnancy is one or two units of alcohol one or two times weekly, but as a cautionary measure advise to abstain [1]. Heavy drinking is classified as: eight or more units for men and six or more for women; binge drinking is double the daily recommendation [2] (for unit guide see Table1). The RCOG guidelines are also reflected in a statement made by the 2007 Deputy Chief Medical Officer Fiona Adshead, who confirmed that alcohol does damage the fetus, and recommended that if women choose to drink before and during pregnancy, then they should adhere to the recommended guidelines [3]. On the other hand, the current guidance from the National Institute for Clinical Excellence (NICE) [4] appears relatively lenient, and states that pregnant women should limit themselves to one unit of alcohol a day.

Although the recommended guidelines for low levels of alcohol remain unclear, there appears to be a consensus that alcohol consumption in pregnancy is an area of 
TABLE 1 Drinkaware guidance regarding the units of alcohol in a variety of drinks (adapted from Drinkaware [5])

\begin{tabular}{llc}
\hline Alcoholic Drink & \multicolumn{1}{c}{ Amount } & Unit Equivalent \\
\hline Beer & 1 pint (4-6\% strength) & 2 \\
Wine & One glass (12\% strength) & 2 \\
Whisky & Single measure (25 ml, 40\% strength) & 1 \\
\hline
\end{tabular}

increasing concern (see Table 2). This is possibly linked to the suggestion of an upward trend in women's consumption of alcohol (see Table 3 ).

A British Medical Association (BMA) report in 2007 [2] identifies that $90 \%$ of women are drinking alcohol on an occasional basis, but there appears to be a marked increase in excessive drinking in younger ones. Another earlier BMA report in 2003 [6] on adolescent health in the UK found that the UK had the highest level of teenage alcohol drinkers (binging or alcoholics) and pregnancies in western Europe. This resulted in the publication's five-point plan for alcohol-free childhood giving the guidance that children should not drink before the age of 15 [7]. It is important to note that the most at risk in women's populations are those that are in situations of high social deprivation or poverty [2]. The 2007 BMA [2] report did not indicate whether teenage drinking, pregnancy, and poverty were related. Table 2 has been provided to indicate the knock on effect of "bad" drinking habits and briefly notes some key issues regarding alcohol intake and reproduction. Both Tables 2 and 3 indicate that "bad" drinking habits will not only harm the fetus during pregnancy, but will impair the reproductive system and have no benefit for the outcomes of pregnancy. In addition, Morgan and Ritson [8] indicated that alcohol exposure at any point in pregnancy can cause damage, therefore suggesting alcohol cessation at any point during pregnancy will benefit the fetus.

Despite the lack of consensus about the safe levels of alcohol consumption in pregnancy, there is increasing evidence of the impact of alcohol on the developing CNS and this will be considered next.

TABLE 2 Identifies some key problems of reproduction that can arise due to alcohol consumption

\begin{tabular}{|c|c|c|}
\hline Topic & Issues & Studies \\
\hline Fertility & $\begin{array}{l}\text { Increases incident of infertility } \\
\text { and menstrual issues. }\end{array}$ & {$[38]$} \\
\hline Miscarriage & $\begin{array}{l}\text { Higher probability to miscarry } \\
\text { due to aneuploidy (results in } \\
\text { birth defects). }\end{array}$ & {$[38]$} \\
\hline \multirow[t]{2}{*}{ Premature and still births } & $\begin{array}{l}\text { High levels of alcohol intake have } \\
\text { been related to increase in } \\
\text { premature births. }\end{array}$ & {$[1]$} \\
\hline & $\begin{array}{l}\text { Low to moderate alcohol intake } \\
\text { has been related to increase in } \\
\text { still births. }\end{array}$ & [39] \\
\hline $\begin{array}{l}\text { Sudden infant death } \\
\text { syndrome (SIDS) }\end{array}$ & $\begin{array}{l}\text { A study by the National Institute } \\
\text { of Child Health and Human } \\
\text { Development (NICHD) and the } \\
\text { National Institute on Alcohol } \\
\text { Abuse and Alcoholism (NIAAA) } \\
\text { found higher risk of SIDS }\end{array}$ & $\begin{array}{l}\text { www.nichd.nih.gov/research/ } \\
\text { supported/pass.cfm }\end{array}$ \\
\hline
\end{tabular}


TABLE 3 Trends in alcohol intake of women of child-bearing age and pregnant

\begin{tabular}{|c|c|c|}
\hline $\begin{array}{l}\text { Age in Years or Number of } \\
\text { Subjects }\end{array}$ & Alcohol Consumption Rate & Studies \\
\hline $8 \%$ of 18 to 24 & 35 units in the previous week & {$[40]$} \\
\hline \multirow[t]{2}{*}{$60 \%$ of 20 to 29} & $\begin{array}{l}\text { Consumed in bouts of heavy } \\
\text { drinking }\end{array}$ & \\
\hline & & {$[41]$} \\
\hline $\begin{array}{l}\text { An increase from } 24 \% \text { to } 28 \% \\
\text { of } 16 \text { to } 24 \text { from } 1998-2000 .\end{array}$ & $\begin{array}{l}6 \text { units or more at least daily in } \\
\text { the previous week }\end{array}$ & {$[42]$} \\
\hline \multicolumn{3}{|l|}{$\begin{array}{l}9 \% \text { of } 16 \text { and above were heavy } \\
\text { drinkers. }\end{array}$} \\
\hline $\begin{array}{l}71 \% \text { of a group of mothers } \\
\text { carried on drinking during } \\
\text { their pregnancy. }\end{array}$ & $\sim 1$ unit weekly & {$[43]$} \\
\hline \multicolumn{3}{|l|}{ Overall, since 1995 mothers in } \\
\hline \multicolumn{3}{|l|}{ UK drinking during } \\
\hline \multicolumn{3}{|l|}{ pregnancy have declined } \\
\hline \multicolumn{3}{|l|}{ (87\% mums had drunk at } \\
\hline \multicolumn{3}{|l|}{6 out of 10 drank during } \\
\hline \multicolumn{3}{|l|}{ pregnancy, 3 out of 10} \\
\hline \multicolumn{3}{|l|}{ abstained during } \\
\hline Out of 500 women: 8 & $\sim 1$ unit per day. One person & {$[44]$} \\
\hline consumed alcohol between & reported maximum intake & \\
\hline 28 - 32 weeks of gestation. & just over two units a day. & \\
\hline \multirow{4}{*}{$\begin{array}{l}\text { Anonymised survey of } 233 \\
\text { random antenatal clinic } \\
\text { attendees in Sheffield } \\
\text { (unpublished data). }\end{array}$} & $45 \%$ zero alcohol intake. & {$[1]$} \\
\hline & $44 \%$ less than 1 unit per day. & \\
\hline & $10 \% \sim 1$ unit per day. & \\
\hline & $1 \%$ more than 1 unit per day. & \\
\hline
\end{tabular}

\section{Potential Impact of Alcohol Exposure on the Developing CNS}

Alcohol is teratogenic, meaning it will affect cellular construction and molecular structures [9]. Hence, alcohol will disrupt proliferation and the migration of cells, which is the focus of early fetal development $[10,11]$. Several in-vitro and in-vivo animal studies (of mice or rats 7 to 16 days post-natal, this is equivalent to the human third trimester that is the synaptogenic period) have shown that changes occur in the developing CNS on a micro level. This is due to alcohol targeting the alcohol-susceptible molecular and cellular structures, involved in proliferation and migration. For example, such susceptible targets are growth factors, glutamate receptors, and neural cell adhesion molecules and these are discussed further in the article.

\section{Growth factors that assist proliferation}

Luo and Miller's [12] review found that both in-vivo and in-vitro animal models show that alcohol exposure during CNS development results in both inhibition and stimulation of cell proliferation. Most of the studies they reported focused on the cerebellum, hippocampus, and cerebral cortex. Neurons and glial cells are involved in proliferative activity for both animals and humans, and interact with each other through polypeptides which are categorized as growth factors also known as neurotrophins (e.g., nerve growth factor (NGF), brain derived growth factor (BDNF), and neurotrophin 3 (NT-3)). In total, cell proliferation is due to mitogenic and nonproliferative growth factors. Mitogen is a protein that signals cell division to occur [11]. Embryo development requires cell proliferation, and alcohol inhibits the growth factors reducing cell proliferation, 

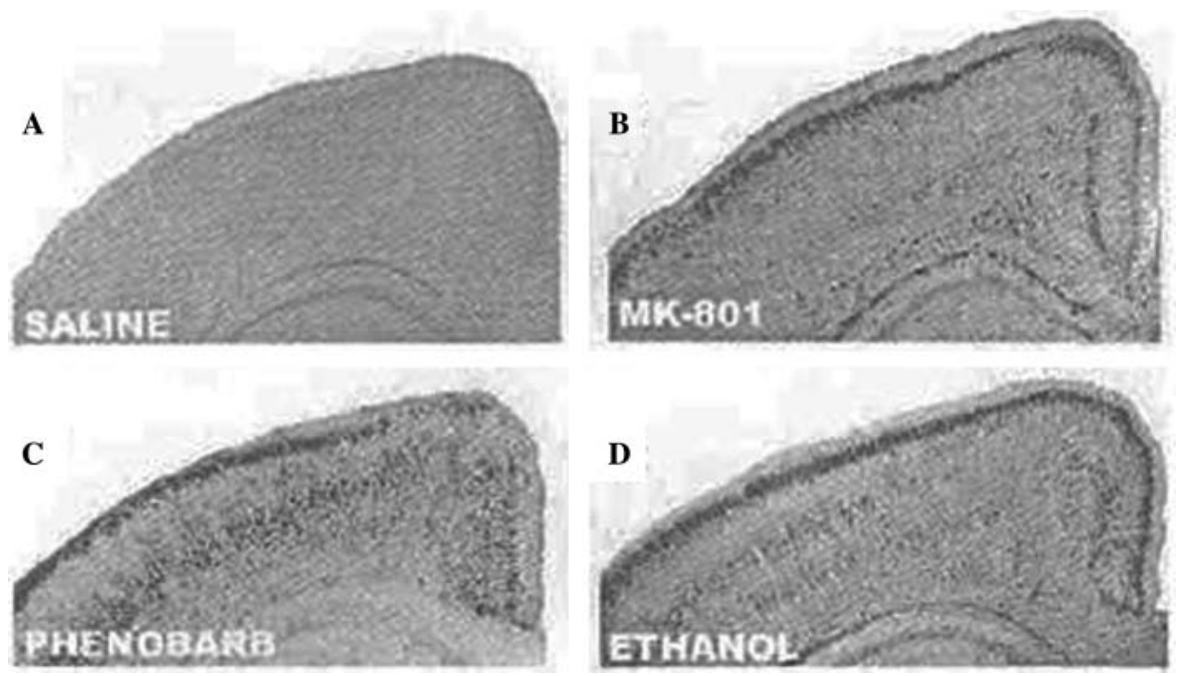

FIGURE 1 Histologic silver and TUNEL-stained slides of 7-day-old Sprague Dawley rat's brain, comparing the apoptotic effects (cell death due to a sequence of events) using solutions of saline, MK801, phenobarbitol, and alcohol (ethanol). The degenerating neurons are identified by dark spots on parts A through D. Parts (A-D) represent the destination of the apoptotic cells in the different solutions. The saline solution revealed a minor pattern of apoptosis due to natural process of eliminating nonviable cells. Compared to (C), the middle cortical layers are relatively spared in (B). Although the NMDA antagonists showed neurodegeneration (C, B), which overlapped with the alcohol, the actual alcohol samples showed a more widespread pattern of neurodegeneration, as seen in (D). Reproduced, with permission, from Elsevier Publishing [17].

notably affecting the G1 phase (beginning of DNA biosynthesis and enzyme synthesis) to develop a cell [10] of the cell cycle.

Alcohol also seems to interfere with the growth inhibiting factors (e.g., transforming growth factor $\beta 1$ (TGF $\beta 1$ )). This results in the stimulation of the dark cycle of the diurnal rhythm of proliferation [12]. The usual rhythm is that more cell proliferation occurs during the light period and less occurs during the dark period [12].

The Luo and Miller's [12] review concludes that alcohol interferes with regulatory activity of mitogenic and inhibiting growth proteins in three ways: cell growth, multiplication, and kinetics. This would not only affect cell proliferation but have a knock on affect on the amount of cells involved in migration.

\section{Apoptosis}

Jacobs and Miller [13] noted that alcohol-treated brain tissue cultures, of 16-day-old rat fetuses, had an increase in the base rate of neuronal death due to acetaldehyde (in general, all fetal brain tissue are susceptible to acetaldehyde, a toxic, and reactive metabolite) identified as promoting apoptosis [14,15].

Alcohol is known to block N-methyl-D-aspartate (NMDA), a glutamate receptor, during the synaptogenesis period of fetal development [16]. Ikonomidou et al's [17] histologic staining study (refer to Figure 1), using light microscopy, investigated the brains of separate groups of 7-day-old Sprague Dawley rats, each group given different solutions 24 h earlier (alcohol, phenobarbitol, MK801 [latter two both NMDA antagonist], and a control group given saline).

Figure 1C superimposed on Figure 1B overlaps with the image in Figure 1D. What was unusual in the alcohol sample (Figure 1D) was that some of the apoptotic regions 
of the brain did not correlate with areas that would usually be affected by NMDA antagonists. Ikonomidou et al. [17] identified through a process of trialing different NMDA agonists and antagonists, a strong apoptotic reaction was triggered when using benzodiazepines and barbiturates which are GABAergic agents (NMDA antagonist) that potentiate GABA (gamma-aminobutyric acid) activity at $\mathrm{GABA}_{\mathrm{A}}$ receptors. The pattern of apoptosis was different from that of the NMDA antagonists, but widespread. By superimposing the neurodegeneration-stained slides of the NMDA and GABA solutions, it was discovered that the collective pattern of neurodegeneration was the same as the alcohol slide [16]. In addition, Toso et al. [18] suggests that alcohol inhibition of the excitatory NMDA receptors originates from stimulation of the inhibitory signaling of GABA receptors. Unusually, the effects of GABA on the rat brain could be seen in vivo but not in vitro; this could be because the insult caused by alcohol requires an intact brain, not cultured tissue, for it to interfere with GABA receptors [20].

Hence, the widespread apoptotic pattern in Figure 1D is due to both the blocking of NMDA receptors and modulating the $\mathrm{GABA}_{\mathrm{A}}$ receptors. This would mean that alcoholinduced apoptotic pathways would be formed to enable apoptotic cells to migrate to destination points. This reduces the number of cells in the developing structure, which would lead to abnormal functioning of the CNS.

\section{Neural cell adhesion molecules (NCAMs)}

Miñana et al.'s [21] study investigated the effect of alcohol on the PSA (polysialic acid)NCAM using several different methods (e.g., western blotting, enzymatic activities, immunochemistry). These molecules are found in both humans and rodents/mice and have the same roles.

Usually PSA-NCAMs are seen in the cytoplasm during the early phase of embryo development, and then are downregulated during cell differentiation at the same time NCAMs are expressed. Neural cell adhesion molecules are homophilic (only interact with cells that are in contact and identical to it at the cell junction) or hetrophilic (only interact with cells that are in contact and not identical to it at the cell junction) binding glycoproteins, which are signalling molecules that can be found on the surface of the cell plasma membranes of neurons and glia cells $[10,15]$. The NCAM gene splices messenger ribonucleic acid (mRNA) at different points, hence producing an NCAM that is homophilic or hetrophilic [22]. Neural cell adhesion molecules are expressed at the end of the post-natal phase for the rat pup, equivalent to the third trimester for humans. These NCAMs are located at the synapses and are involved in stabilizing the synapse and are crucial in the processes involved in developing the CNS (e.g., axonal growth, morphogenesis, migration, and plasticity) [23].

One experiment from Miñana et al.'s [21] study, which used immunogold-labelling of brain tissue of prenatal alcohol exposed 7-day-old rat pups, identified that PSANCAM accumulated in the cytoplasm, reducing expression of NCAMs in the plasma membrane. Immunogold ligand was used to locate antiNCAM and antiPSA-NCAM antibody binding sites; they recognize NCAMs and PSA-NCAMs, respectively (although the former can recognize PSA-NCAM as well). Astroglia were represented by anti-GFAP [glial fibrillary acidic proteins] an antigen selective marker for astroglia cells and the presence of intermediate filaments (IF).

Astroglia cells were recognized by their shape and immunocytologic characteristic from previous literature. Anti-GFAPs were recognized by $5 \mathrm{~nm}$ particles gold and any NCAMs by $10 \mathrm{~nm}$ length gold particles. The experimental results indicated PSANCAM levels in the alcohol (ethanol) exposed cytoplasm increased significantly by two-fold in comparison to the control (62\% PSA-NCAM in this cytoplasm), resulting in a decrease of NCAM in the plasma membrane, and structural changes (maladaptive effects on axonal growth, glia proliferation, and migration). 
TABLE 4 Identifying the teratogenic features of ethanol (adapted from [2], page 8)

\begin{tabular}{|c|c|}
\hline Potential Mechanisms of Ethanol Teratogenesis & Description \\
\hline Disruption of cellular energetics & $\begin{array}{l}\text { Cellular energetics is the chemical movements } \\
\text { required for events to occur. In this case } \\
\text { changes can result in glucose uptake and } \\
\text { transport, prevent protein and DNA synthesis, } \\
\text { oxidative stress. }\end{array}$ \\
\hline $\begin{array}{l}\text { Impairment of cell acquisition or dysregulation } \\
\text { of development timing }\end{array}$ & $\begin{array}{l}\text { Interference with the normal movements in the } \\
\text { cell cycle, cell generation, migration, } \\
\text { synaptogenesis, formation of myelin, } \\
\text { neurogenesis and gliogenesis }\end{array}$ \\
\hline Disruptions of cell to cell interactions & $\begin{array}{l}\text { "inhibitions of } \mathrm{L} 1 \text { cell adhesion molecule (L1 } \\
\text { CAM) function" }\end{array}$ \\
\hline $\begin{array}{l}\text { Interference with growth factor signaling or } \\
\text { other cell-signalling pathways }\end{array}$ & $\begin{array}{l}\text { Reduced capabilities of the the NMDA } \\
\text { receptors, retardation in the formation of the } \\
\text { serotonin system, suppression of the } \\
\text { insulin-like growth factors I \& II }\end{array}$ \\
\hline Cell damage or death & $\begin{array}{l}\text { Apoptosis, oxidative stress, glutamatergic } \\
\text { excitability }\end{array}$ \\
\hline $2^{0}$ sources of damage & $\begin{array}{l}\text { Compromised placental capability, hypoxia, } \\
\text { acetaldehyde build up }\end{array}$ \\
\hline
\end{tabular}

There are other teratogenic effects of alcohol exposure, beyond the scope of this article. But the three areas indicated confirmed that, in general, during CNS development alcohol will target alcohol-susceptible cells and molecules involved with proliferation and migration. Table 4 provides a list, collated by the BMA [2], of mechanisms that could be targeted by alcohol in the developing CNS, including the three discussed.

The contribution of any one mechanism does not singularly lead to dysfunction of the developing fetal CNS; it is a multi-factorial integrated process.

The studies considered provide evidence that alcohol affects the developing CNS when drinking excessively or multiple binge exposure. The experiments identified do not model low levels of alcohol exposure, although the RCOG [1] says overall the evidence in this area is unclear. However, Ieraci and Herrera [24] did study a one-off event of binge drinking in a mouse model. They found that a single binge exposure of alcohol on a 7-day-old mouse resulted in reduction in neurogenesis in the hippocampus during adulthood, due to reduced availability of stem and progenitor cells [24]. Therefore, one episode of severe drinking could potentially leave long-lasting CNS damage.

The animal models, of excessive alcohol drinking and binge exposures, provide a basis from which we can understand the potential mechanisms resulting in problems that could occur for the fetus or child. However, it is important to keep in mind that the research results are from animal studies and have yet to be confirmed in humans [25]. Even though the evidence for low levels of alcohol and fetal harm is inconclusive, the damage caused by excessive consumption is more evident as illustrated by the occurrence of fetal alcohol syndrome.

\section{Fetal Alcohol Syndrome (FAS)}

Alcohol is fetotoxic, and FAS is evidence of this [9]. Fetal alcohol syndrome or fetal alcohol affects (FAE) indicates an extreme end of a continuum of effects as a result of teratogenic effects of alcohol consumption during pregnancy. Its occurrence in Europe is estimated at 0.08 per 1000 live births [26]. Other less extreme forms are alcohol-related birth defects (ARBD) or alcohol-related neurodevelopmental disorders (ARND) [27]. Metabolized alcohol enters the embryo through the metabolic actions within the placenta, as the developing fetus itself does not have the ability to metabolize the alcohol 
$[28,2]$. The sensitivity of the developing fetus to alcohol exposure occurs during three separate periods $[29,9]$ :

- first trimester, predifferentiation - this stage is focused on cellular proliferation and migration, the embryo has a capacity to recover from insult or dies;

- second trimester, 10-20th weeks - alcohol exposure results in most of the clinical features of FAS, complex activity of laying the foundations of its various structures;

- third trimester, hippocampus susceptibility - alcohol is fetogenic, a presentation of this is hippocampus damage resulting in learning, hearing, and visual processing problems, in general, alcohol exposure at this point can result in retardation of growth and development of the fetus.

There is documentation that Aristotle warned women that excessive drinking produced offspring that were not "normal" [30]. In 1726, the Royal College of Physicians described the offspring of mothers who drank too much as "weak, feeble, and distempered children, who must be instead of an advantage and strength, a charge to their Country" [30, p. 169]. But the first official medical publication on FAS was French, by Lemoine et al. in 1968; they collected data from 100 children of woman who were categorized as heavy drinkers [30]. It has been found that women who drink more then $35 \mathrm{~g}$ of alcohol a day will be three times more likely to have babies with CNS structural deformities than women who do not drink or drink less [1] This is further supported by imaging studies that have enabled associations to be made between the changes in the brain and neuro-behavioral features of FAS $[31,19]$. Some of the regional changes in the brain have been identified in the neocortex, hippocampus, and cerebellum which are susceptible to alcohol exposure [32]; and prominent reduction of white matter and parietal lobes of children exposed to prenatal alcohol [32]. Figure 2 shows some of the structural changes that occur due to fetal alcohol exposure and related consequences.

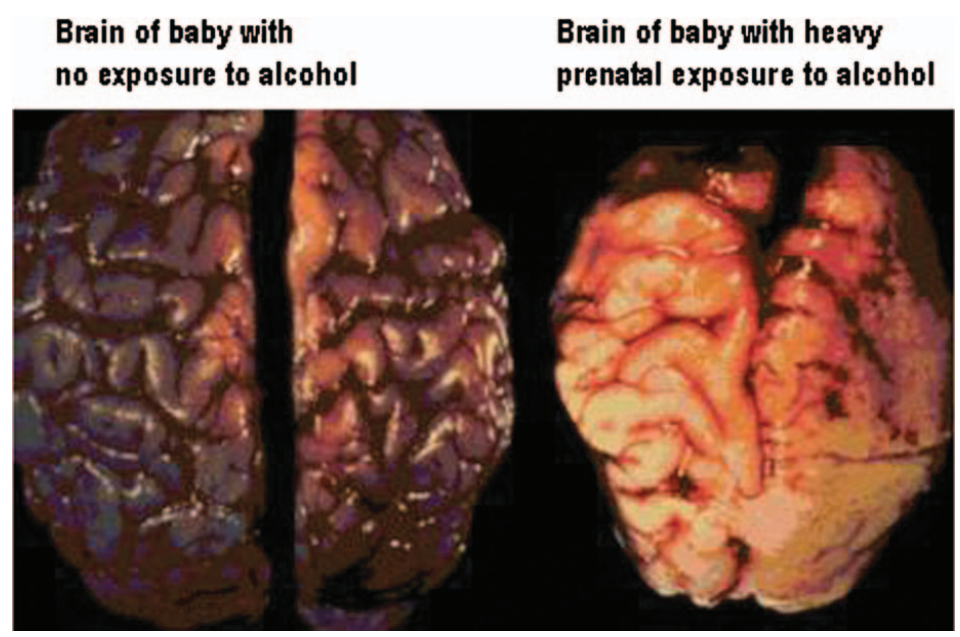

FIGURE 2 Brain of baby with no exposure to alcohol (left); brain of baby with heavy prenatal exposure to alcohol (right) [29]. The right brain is smaller and smoother in comparison and has less white matter (hypoplasia). The brain on the right is an extreme example of damage and over $85 \%$ of brains damaged by alcohol have anatomical changes that are so subtle that they cannot be seen with the naked eye or clinical imaging [19]. If the baby on the right survived and matured, due to the resulting structural deformities of the brain, there would be developmental and functional problems for this person. Reproduced, wth permission, from Sterling K. Clarren, MD, FAAP, 28 November 2010 . 

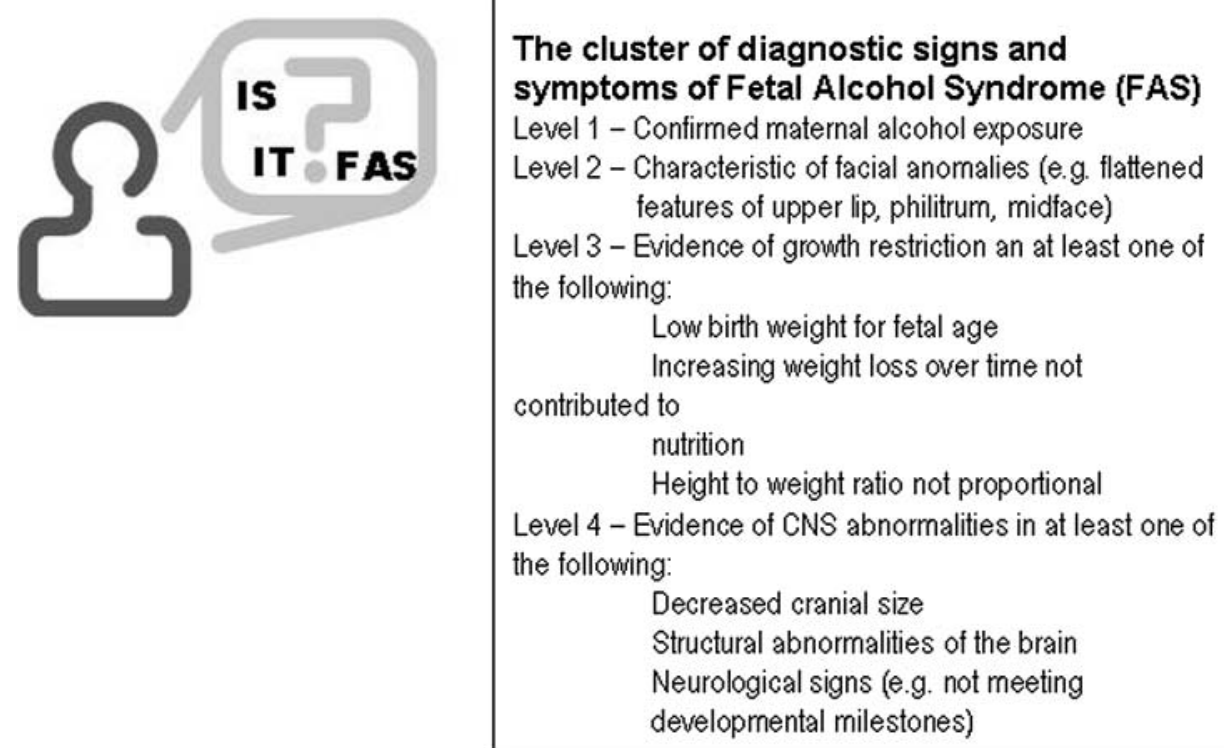

FIGURE 3 The cluster of diagnostic signs and symptoms of Fetal Alcohol Syndrome (adapted from $[1$, pages $6 \& 25])$.

Moreover, it is surprising to see in Figure 2, the structural differences in a normal and FAS brain. Figure 3 identifies the diagnostic cluster of signs and symptoms of FAS. It is important to point out that due to structural abnormalities of the brain the children may also have epilepsy, autism, hyperactivity-related issues, learning disabilities, hearing problems, visual problems, and some cognitive/perceptual problems $[28,10]$. Studies of children diagnosed with FAS at the age of 7 have shown low academic ability, impulsiveness, and hyperactivity [1].

The diagnosis of FAS is through a process of elimination because there are many genetic syndromes that are similar and have similar clinical presentations [1]. Therefore, children of mothers who drink should not automatically be diagnosed with FAS, if they show some clinical signs.

Mukherjee and Turk [26] warn that the figures, stated for the occurrence of FAS in Europe, appear to be underestimated in comparison to the 9.1 per 1000 live births for the world. They go on to add that the UK is ill prepared for the potential increase in this syndrome or related disorders, projected long term care into adulthood, and the ensuing costs of care [26].

\section{Is There Any Form of Neuroprotection for the Developing Fetus Against FAS?}

Although a substantial number of papers have been published on the effect of alcohol intake and the development of the fetus, there is a growing body of work investigating how to protect the fetus against alcohol exposure. Two such studies are briefly discussed below.

\section{Activity-dependent peptides}

Sari and Gozes [33] reviewed the effects of activity-dependent neurotrophic factor (ADNF-9 or alternate name SAL), and activity-dependent neuroprotective protein (ADNP or NAP) expressed and synthesized by astroglia, on a mouse model of FAS/FAE (exposure to alcohol in utero). Activity-dependent neurotrophic factor is 
already known for its cellular neuroprotective qualities and is an essential peptide for its survival. Activity-dependent neuroprotective protein is neuroprotective against oxidation leading to apoptosis and is expressed during neural tube closure [34,33]. They found that NAP-treated cultures were protected against alcohol effects, but not SAL; a combination treatment had an enhanced neuroprotective effect, implying that both are needed to prevent growth retardation [35,33]; the prenatal alcohol-exposed and peptide-treated adult mice were tested in the Morris maze. The results show deterioration in learning ability for the former but no marked impairment in learning for the latter compared to controls. The mechanisms for this neuroprotection are not quite clear but more studies are required for further enquiry.

\section{Lithium}

This study investigated the effect of lithium on alcohol-treated cultures of immature rat neurons. They noted a decrease of $23 \%$ and $50 \%$ of apoptotic cell in the striatum and frontal cortex, respectively. Lithium is said to inhibit GSK3 $\beta$, this substance encourages neuronal death. This agreed with previous studies that have shown lithium neuroprotection against apoptosis, triggered by a lack of potassium, $\beta$ amyloid, and glutamate [36,37].

More investigations are required, but this does bring forward the possibility of substances that could protect against alcohol exposure. The side effects of the substances would have to be investigated too, for example, the side effects of lithium might mitigate its use in pregnancy.

\section{CONCLUSION}

The mounting evidence indicates that alcohol has no overall benefit for pregnancy and its outcomes. This evidence mostly from animal models suggests that alcohol and its metabolites are cytotoxic on the cellular physiology of the developing fetus at any point during pregnancy; and this relates to excessive intake or several binge episodes. This is confirmed by the occurrence of FAS in offspring, of mothers who drank excessively during pregnancy. However, there is research arising around neuroprotection as a useful route to ensure the safety of the fetus, when their mothers are alcoholics or persistent binge drinkers and unable to abstain. The limited evidence on studies of the effects of low levels of alcohol consumption and its inconclusive outcomes, do not support abstinence, although this is the recommended option.

\section{ACKNOWLEDGEMENT}

I would like to acknowledge Dr. Jolanta Opacka-Juffry, Principal Lecturer and my personal tutor when I did my MSc in Clinical Neuroscience, Department of Life Sciences, Roehampton University, Surrey, UK.

\section{Declaration of Interest}

The author reports no conflicts of interest. The author alone is responsible for the content and writing of the paper.

\section{REFERENCES}

[1] Royal College of Obstetricians and Gynaecologists. Alcohol consumption and the outcomes of pregnancy statement no. 5. http://www.rcog.org.uk/resources/ Public/ pdf/alcohol_pregnancy_rcog_ statement5a.pdf, 2006. Last accessed 28/10/07. 
[2] British Medical Association Fetal Alcohol Spectrum - A guide for healthcare professionals. London: British Medical Association: http://www.nofas-uk.org/ PDF/BMA\%20REPORT\%204\%20JUNE\% 202007.pdf, 2007. Last accessed 20/10/07.

[3] Department of Health Alcohol and Pregnancy. http://www.dh.gov.uk/en/News/ DH_074968, 2007. Last accessed 28/10/07.

[4] NICE. Antenatal care: routine care for pregnant healthy women. http://www.nice.org. uk/pdf/ CG6_ANC_NICEguideline.pdf, 2003. Last accessed 28/10/07.

[5] Drinkaware. Drinkaware.co.uk for the facts. http://www.drinkaware.co.uk/tips-and-tools/drinkdiary, 2010. Last accessed 19/10/2010.

[6] British Medical Association Adolescent Health. London: British Medical Association http://www. bma.org.uk/health_promotion_ethics/child_health/AdolescentHealth.jsp, 2003. Last accessed $19 / 10 / 2010$.

[7] Department for Children, Schools and Families. Every child matters - Five-point plan for alcohol-free childhood. http://www.dcsf.gov.uk/everychildmatters/news-and-communications/ news/290109nialcoholfreechildhood, 2009. Last accessed 19/11/2010.

[8] Morgan MY, Ritson EB. Alcohol and Health: A Handbook for Students and Medical Practitioners Medical Council on Alcohol. London: Medical Council on Alcohol, 2003.

[9] Pollard I. Neuropharmacology of drugs and alcohol in mother and fetus. Seminars in Fetal and Neonatal Medicine 12:106-13, 2007.

[10] Purves D, Augustine GJ, Fitzpatrick D, Hall WC, LaMantia A-S, McNamara JO, Williams SM. Neuroscience, 3rd ed. Massachusetts, Sunderland, MA: Sinauer Associates Inc., 2004.

[11] Bear MF, Connors BW, Paradiso MA. Neuroscience Exploring the Brain Philadelphia: Lippincott Williams \& Wilkins, 2007.

[12] Luo G, Miller MW, Growth factor-mediated neural proliferation: target of ethanol toxicity. Brain Research Reviews 27:157-67, 1998.

[13] Jacobs JS, Miller MW. Proliferation and death of cultured fetal neocortical neurons: effects of ethanol dynamics of cell growth. Journal of Neurocytology 30:391-401, 2001.

[14] Holownia A, Marc Ledig M, Braszko JJ, Ménez J-F. Acetaldehyde cytotoxicity in cultured rat astrocytes. Brain Research 833(2):202-8, 1999.

[15] Guerri C, Pascual M, Renau-Piqueras J. Glia and fetal alcohol syndrome. NeuroToxicology 22:593-9, 2001.

[16] Ikonomidou C, Bittigau P, Koch C, Genz K, Hörster F, Felderhoff-Mueser U, Tenkova T, Dikranian $\mathrm{K}$, Olney JW. Neurotransmitters and apoptosis in the developing brain. Biochemical Pharmacology 62:401-5, 2001.

[17] Ikonomidou C, Bittigau P, Ishimaru MJ, Wozniak DF, Koch C, Genz K, Price MT, Stefovska V, Hörster F, Tenkova T, Dikranian K, Olney JW. Ethanol-induced apoptotic neurodegeneration and fetal alcohol syndrome. Science 287:1056-60, 2000.

[18] Toso L, Roberson R, Woodard J, Abebe D, Spong CY. Prenatal alcohol exposure alters GABAA $\alpha 5$ expression: A mechanism of alcohol-induced learning dysfunction. American Journal of Obstetrics and Gynaecology 195:522-7, 2006.

[19] Toga AW, Thompson PM, Sowell ER. Mapping brain maturation. Trends in Neurosciences 29(3):154-9, 2006.

[20] Hsaio S-H, DuBois DW, Miranda RC, Frye GD. Critically timed ethanol exposure reduces GABAAR function on septal neurons developing in vitro but in not in vitro. Brain Research 1008:69-80, 2004.

[21] Miñana R, Clement E, Barettino D, Segui JM, Renau-Piqueras J, Guerri C. Alcohol exposure alters the expression pattern of neural cell adhesion molecules during brain development Journal of Neurochemistry 75(3):954-64, 2000.

[22] Cunningham BA, Hemperly JJ, Murray BA, Prediger EA, Brackenbury R, Gerald M, Edelman GM. Neural cell adhesion molecule: structure, immunoglobulin-like domains, cell surface modulation, and alternative RNA splicing Science 236:799-806, 1987.

[23] Bearer CF. L1 cell adhesion molecule signal cascades: targets for ethanol developmental neurotoxicity. NeuroToxicology 22:625-33, 2001.

[24] Ieraci A, Herrera DG. Single alcohol exposure in early life damages hippocampal stem/progenitor cells and reduces adult neurogenesis. Neurobiology of Disease 26:597-605, 2007.

[25] Clarren S Researchers search result - Child \& Family research institute. http://www.cfri.ca/ our_research/researchers/search_researchers/researcher_detail.asp?ID=25, 2009. Last accessed $20 / 11 / 2010$.

[26] Mukherjee RAS, Turk J Fetal alcohol syndrome. Lancet 363:1556, 2004.

[28] Itthagarun A, Nair RG, Epstein JB, King NM. Fetal alcohol syndrome: case report and review of literature. Oral Surgery, Oral Medicine, Oral Pathology, Oral Radiology \& Endodontics 103;e20-e25, 2007. 
[27] Taylor AN, Chiappelli F, Tritt SH, Yirmiya R, Romeo HE. Fetal alcohol syndrome, fetal alcohol exposure and neuro-endocrine-immune interactions. Clinical Neuroscience Research 6:42-51, 2006.

[29] Kellerman T. Prenatal alcohol exposure and the brain. http://www.come-over.to/FAS/FASbrain .htm, 2006. Last accessed 11/11/07.

[30] Calhoun F, Warren K. Fetal alcohol syndrome: Historical perspectives Neuroscience and Biobehavioural Reviews 31:168-71, 2007.

[31] McGee CL, Riley EP. Brain imaging and fetal alcohol spectrum disorders. Annali dell Istituto Superiore di Sanitá 42(1):46-52, 2006.

[32] Guerrini I, Thomson AD, Gurking HD. The importance of alcohol misuse, malnutrition and genetic susceptibility on the brain growth and plasticity. Neuroscience and Biobehavioural Reviews 21:212-20, 2007.

[33] Sari Y, Gozes I. Brain deficits associated with fetal alcohol exposure may be protected, in part, by peptides derived from activity-dependent neurotrophic factor and activity-dependent neuroprotective protein. Brain Research Reviews 52:107-18, 2006.

[34] Gozes I, Steingart RA, Spier AD. NAP mechanisms of neuroprotection. Journal of Molecular Neuroscience 24(1):67-72, 2004.

[35] Spong CY, Abebe DT, Gozes I, Brenneman DE, Hill JM. Prevention of fetal demise and growth restriction in a mouse model of fetal alcohol syndrome. Journal of Pharmacology and Experimental Therapeutics 297(2):774-9, 2001.

[36] Rowe MK, Chuang D-M. Lithium neuroprotection: molecular mechanisms and clinical implications. Expert Reviews in Molecular Medicine 6(21):1-18, 2004.

[37] Zhong J, Yang X, Yao W. Lee W. Lithium protects ethanol-induces neuronal apoptosis. Biochemical and Biophysical Research Communications 350:905-10, 2006.

[38] Jensen et al. Does moderate alcohol consumption affect fertility? Follow up study among couples planning first pregnancy. British Medical Journal 317:505-10, 1998.

[39] Kesmodel et al. Moderate alcohol intake during pregnancy and the risk of stillbirth and death in the first year of life. American Journal of Epidemiology 155:305-12, 2002.

[40] Plant \& Plant. Heavy drinking by young British women gives cause for concern. British Medical Journal 323:1183, 2001.

[41] Parliamentary Office of Science \& Technology. Binge drinking and public health. London: The Parliamentary Office of Science and Technology, 2005.

[42] ONS. Results from the 2003 General Household Survey. London: Her Majesty's Stationery Office. 28 Parliamentary Office of Science, 2005.

[43] Hamlyn et al. Infant feeding survey 2000. National Health Service Information Centre. London: Her Majesty's Stationery Office, 2002.

[44] James et al. Alcohol consumption during pregnancy in Bristol. J Obstet Gynaecol 15:86-7, 1995. 